\title{
I 58 A contrast dose reduction study for 3D high spatial resolution contrast-enhanced magnetic resonance angiography of supra-aortic arteries at 3.0 Tesla
}

\author{
Anderanik Tomasian*, Noriko Salamon, Derek G Lohan, Mayil S Krishnam, J \\ Pablo Villablanca and J Paul Finn
}

Address: UCLA, Los Angeles, CA, USA

* Corresponding author

from I th Annual SCMR Scientific Sessions

Los Angeles, CA, USA. I-3 February 2008

Published: 22 October 2008

Journal of Cardiovascular Magnetic Resonance 2008, I0(Suppl I):A59 doi:10.1 I86/1532-429X-I0-SI-A59

This abstract is available from: http://jcmr-online.com/content/I0/SI/A59

(c) 2008 Tomasian et al; licensee BioMed Central Ltd.

\section{Introduction}

Recent advances in contrast-enhanced MR angiography (CE-MRA) at 3.0 T support highly accelerated parallel acquisition for improved pulse sequence performance. In clinical practice, CE-MRA of the supra-aortic arteries is performed using $0.1-0.2 \mathrm{mmol} / \mathrm{kg}$ of gadolinium. Historically, this has been a very uncontroversial area, in view of the excellent safety record of gadolinium contrast agents and the assumed correlation between image quality and contrast dose. However, recent reports linking gadolinium-based contrast agents with nephrogenic systemic fibrosis (NSF) in renal failure patients has focused attention on the importance of minimizing dose and (by implication) risk in vulnerable patient subgroups.

Currently, no validated approach exists for the selection of minimal or optimal contrast dosing for MR angiography of the head and neck arteries at 3.0 T. Relative to high dose or intermediate dose protocols at $3.0 \mathrm{~T}$, low-dose contrast infusion protocols may result in MR angiograms of diagnostic quality, while diminishing cost and the risk of dose-dependent complications in susceptible populations.

\section{Purpose}

To prospectively compare the diagnostic image quality resulting from three dose regimens for high-spatial resolution 3D contrast-enhanced MR angiography of supra-aortic arteries at 3.0 $\mathrm{T}$.

\section{Methods}

100 consecutive patients were randomized into three groups ( $\mathrm{A}, \mathrm{n}=40 ; \mathrm{B}, \mathrm{n}=40 ; \mathrm{C}, \mathrm{n}=20$ ) and underwent $3 \mathrm{D}$ high-spatial resolution CEMRA of supra-aortic arteries at 3.0 T (Trio, Siemens) using an identical acquisition protocol. A fast spoiled gradient-echo sequence with parallel acquisition (GRAPPA $\times 4$ ) generated 120 partitions (voxel dimensions $\left.0.7 \times 0.7 \times 0.8 \mathrm{~mm}^{3}\right)$ in 21 seconds. The contrast injection protocols were 1) $25 \mathrm{~mL}$, 2) $15 \mathrm{~mL}, 3) 7.5$ $\mathrm{mL}$ of Magnevist (Berlex Laboratories, Wayne, $\mathrm{NJ}$ ) at a rate of $0.8,0.5$, and $0.25 \mathrm{mmol} / \mathrm{sec}$, respectively. Supra-aortic arterial territory was divided into 34 segments and assessed for visibility of arterial segments, venous contamination, and severity of stenosis (4-point scales) by two readers. Signal-to-noise ratio (SNR) and contrast-to-noise ratio (CNR) was also evaluated. Statistical analysis was performed using Wilcoxon, ANOVA, and kappa test.

\section{Results}

Reader 1 and 2 identified arterial delineation as sufficient for diagnosis or excellent in group A for 1311 (96.4\%) and $1313(96.6 \%)$ segments, in group B for1321 (97.6\%) and 1319 (97.4\%) segments, and in group C for 658 $(97.5 \%)$ and $662(98.1 \%)$ segments, respectively (good inter-observer agreement). Reader 1(2) identified venous contamination in 24 (21), 15 (11), and 11(9) segments, and arterial stenosis in 52(48), 27 (25), and 31(29) segments in groups $\mathrm{A}, \mathrm{B}$, and $\mathrm{C}$, respectively (excellent interobserver agreement). No significant difference existed 
between arterial delineation and venous contamination scores for each reader between the three groups $(\mathrm{P}>0.05)$. SNR and CNR values were significantly lower in group $C$ compared to groups A and B.

\section{Conclusion}

High-spatial resolution CEMRA of the supra-aortic arteries at $3.0 \mathrm{~T}$ can be performed with a gadolinium dose as low as $0.05 \mathrm{mmol} / \mathrm{kg}$ without compromising image quality. Adoption of low-dose protocols should diminish sensitivity to dose-dependent complications and result in substantial cost savings.

Publish with Biomed Central and every scientist can read your work free of charge

"BioMed Central will be the most significant development for disseminating the results of biomedical research in our lifetime. " Sir Paul Nurse, Cancer Research UK

Your research papers will be:

- available free of charge to the entire biomedical community

- peer reviewed and published immediately upon acceptance

- cited in PubMed and archived on PubMed Central

- yours - you keep the copyright

Submit your manuscript here:

http://www.biomedcentral.com/info/publishing_adv.asp 